\title{
Low Vertical Car Parking Automatic Control System Using Programmable Logic Control
}

\author{
Setyo Supratno ${ }^{1}$ Seta Samsiana ${ }^{1, *}$ Aeri Sujatmika ${ }^{1}$ Muhamad Fajar Hermawan ${ }^{1}$ \\ ${ }^{1}$ Teknik Elektro, Unversitas Islam 45 Indonesa \\ *Corresponding author.Email: set4sam@gmail.com
}

\begin{abstract}
A vertical car parking automatic control system using PLC is a prototype system which is intended to minimise the use of car parking size. This prototype is created with a maximum capacity of six cars which will be parked vertically. The vertical car parking automatic control system will use a Mitsubishi FX3G PLC. In addition, a position sensor that will be used in a E50S8-3600-3-T-24 rotary encoder of Autonic. This rotary encoder will send pulse signal to PLC which will process the signal and measure a swivel angle. The pulse signal produced by the sensor of rotary encoder is changed by PLC into a bit data so that it can be processed in the form of logic equations which will be arranged into a Ladder Diagram program. The results show that the fastest time period for the system to reach the set point is 4 seconds while the longest is 8 seconds, making the average time period is 5.6 seconds.
\end{abstract}

Keywords: Vertical Car Parking, Control System, PLC, Sensor Rotary Encoder.

\section{INTRODUCTION}

Currently the number of motorized vehicles such as cars is increasing, especially in big cities such as Jakarta and Bekasi, due to the increasing number of motorized vehicles, the more parking lots must be provided. Reviewing the need for parking space in office, school and supermarket areas, where car drivers are concerned about the convenience of parking due to the difficulty of getting a parking space [6]. Seeing the limited parking space, it is necessary to design and design a system that can make parking lots more efficient [2]. The automatic control system is a system that is used to make it easier for humans to do their jobs [10]. With this system, it is hoped that the limited land can be used to load more vehicles. This parking system is designed to be efficient and effective in today's parking problems [4]. In addition, it is also necessary to make a system that can minimize the effects of a less than optimal system [11]. An automatic system is needed to make it easier for humans to run. Because in addition to human limitations in working speed, and also the problem of saturation which can lead to fatal negligence [1], [3].

Based on the foregoing, a solution is needed to be designed for an automatic parking system [9]. In order to streamline the limited land so that it can load more vehicles, it is necessary to make a vertical car park design [8]. This research is a vertical car parking automatic control system design using Mitsubishi FX-3G PLC [7]. PLC is used because it has advantages that are relevant to the design needs of this system. Among the advantages of using a PLC device is the ability to work in harsh conditions, for example damp conditions, high temperatures and high frequencies [5]. To determine the position of the car in the vertical car park device, a rotary encoder is used because it can calculate the turning angle in combination with a PLC device. With this design, it is hoped that the availability of parking space can be proportional to the increase in the number of fourwheeled vehicles which continues to increase every year, [4].

The purpose of this research, among others, is to be able to place the parking position vertically upwards, a control system designed and implemented aims to be able to get the fastest time to call a parked car on a prototype of a vertical car parking device. In addition, the goal of this research is to be able to move the car's position in or out with a button press command. With the above objectives, several problem formulations are needed, namely how to design a prototype tool that represents the car park conditions vertically upwards. In addition, the formulation made is how to design and implement an automatic control system for a vertical car parking prototype. 


\section{METHOD}

This research was carried out based on the steps as explained in the research procedure flow chart which can be seen in Figure 1. System design includes electronics and mechanics by drawing details and the layout of the components of the mechanical and electronic systems being built. The design of electronic systems includes the need for a power supply source and a device that functions as an automatic control system.

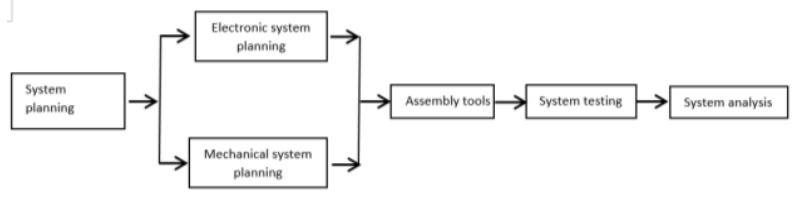

Figure 1 Flowchart of Research Procedure

The design of electronic systems:

1. A single-phase main power supply in the form of an alternating voltage of 220 Volt is used to supply the inverter and PLC. The main power supply is current limited by a miniature circuit breaker (MCB) device with a capacity of 6 Ampere so that when there is a problem with the circuit or electronic device, the MCB will cut the mains electric current (Figure.2)

2. The Mitsubishi Freeroll S-500 type inverter device $0.20 \mathrm{KW}$ with a 1-phase power supply in the form of a 220 Volt AC voltage is converted into a 3-phase 220 Volt AC voltage which is used as a power supply to generate an induction motor to rotate. The inverter also functions as an electric frequency regulator so that the rotation speed of the induction motor can be adjusted.

3. PLC device with a single-phase power supply in the form of 220 Volt AC voltage which functions as the center for automatic control of the vertical car parking system. PLC has several main functions, including the CPU or Central processing unit as the control center and as a programming connection that is connected to the computer. The input function in the form of a button and rotary encoder is a command to be processed on the CPU. The output function is the result of the input response that has been processed on the CPU in the form of a voltage signal that is sent to the relay then gives an order to the inverter to drive the induction motor.

4. On the PLC device there is a power supply in the form of a direct voltage that is 24 Volt DC with a capacity of 2 Ampere. 24 Volt DC voltage is used to carry out the functions of the PLC input and output devices. 24 Volt direct voltage power supply is also used as a pulse signal generator in rotary encoder devices.

5. The incremental type rotary encoder device functions as a position sensor where the rotary encoder can generate pulse signals. The pulse signal generated from the rotary encoder is useful for controlling and determining the angle of rotation of the induction motor. The pulse signal is connected to a PLC which can calculate so that the motor rotation angle can be determined so that the slot position and motor rotation can be adjusted.

6. A laptop or computer is used to be able to integrate all devices into a single automatic system. A computer or laptop is used to create programs for later upload to the PLC. A computer or laptop can also function as a monitoring device for working devices.

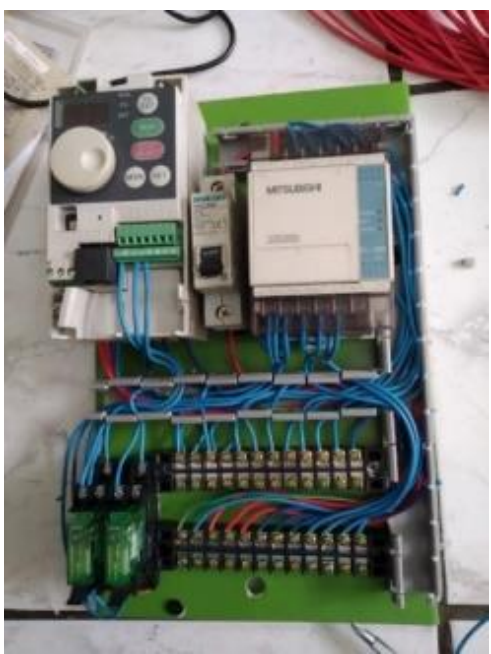

Figure 2 The process of installing power and power cables

The design of the mechanical system includes the design of the prototype of a vertical car parking system, including iron construction, determining the layout of the mechanical components in order to be sustainable with each other. The mechanical system design also determines the exit and entry positions of the car as a means of system simulation. In addition, the location of the control panel which functions as the central processing of control signals is illustrated. Figure 3 shown mechanical component layout assembly process.

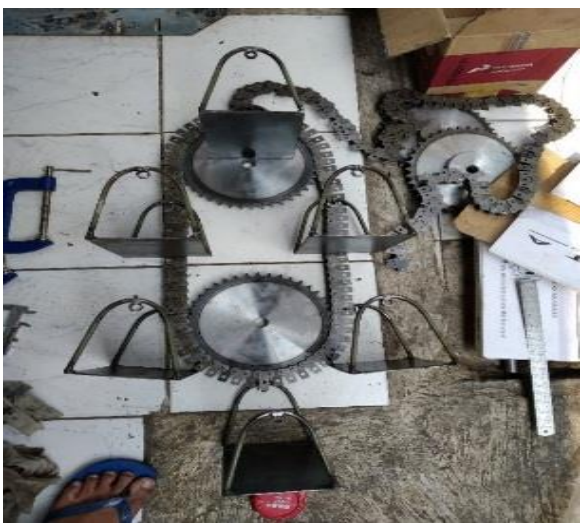

Figure 3 Mechanical component layout assembly process 
The assembly of mechanical tools includes the manufacture of steel construction, installation of mechanical components such as chains, bearings and gears in steel construction, painting of mechanical devices to avoid corrosion. Electronic assembly includes 24 Vdc Power Supply Circuit, Mitsubishi F3GS PLC, 3 Phase Induction Motor Circuit, Incremental Encoder Circuit.

System testing includes Voltage (V) and Current (I) used in the induction motor, $24 \mathrm{Vdc}$ Power Supply obtained from the PLC internal power supply, Relay 24 VDC, pulses on the rotary encoder which affect the angular position of the motor rotation.

Data analysis includes the process of data collection and data processing based on the literature that has been described. After the data is collected and processed, the results can be drawn to draw conclusions from this research.

\section{RESULT AND DISCUSSION}

Testing of electronic system design includes measuring the voltage and electric current used for consumption of an electric motor as a driving force. In addition, testing of the electronic system is carried out by testing the accuracy of the command of the tool with the actual carried out by the system. This test wants to show that the rotary encoder device has a function to read the position of the motor rotation angle and can be controlled by the PLC. Here is a test table for the control system (Table 1-6).

Table 1. test with initial position in slot 1 and Measuring voltage \& electric current on the test

\begin{tabular}{|c|c|c|c|c|c|c|c|c|c|c|c|c|}
\hline \multirow{2}{*}{ Trial } & \multirow{2}{*}{$\begin{array}{l}\text { Set } \\
\text { point }\end{array}$} & \multirow{2}{*}{$\begin{array}{l}\text { Present } \\
\text { value }\end{array}$} & \multirow{2}{*}{ Time } & \multirow{2}{*}{$\begin{array}{l}\text { input } \\
\text { voltage } \\
\text { (V) } \\
\text { Fasa- } \\
\text { netral }\end{array}$} & \multicolumn{2}{|c|}{ output voltage $(\mathrm{V})$} & \multicolumn{3}{|c|}{$\begin{array}{c}\text { input } \\
\text { current(A) }\end{array}$} & \multicolumn{3}{|c|}{ output current(A) } \\
\hline & & & & & R-S & $\mathrm{R}-\mathrm{T}$ & S-T & Fasa & Net & $\mathrm{R}$ & $\mathrm{S}$ & $\mathrm{T}$ \\
\hline 1 & 1 & slot 2 & 4 & 225 & 182 & 182 & 182 & 0.2 & 0.2 & 0.2 & 0.2 & 0.2 \\
\hline 2 & 2 & slot 3 & 6 & 225 & 182 & 182 & 182 & 0.2 & 0.2 & 0.2 & 0.2 & 0.2 \\
\hline 3 & 3 & slot 4 & 8 & 225 & 182 & 182 & 182 & 0.2 & 0.2 & 0.2 & 0.2 & 0.2 \\
\hline 4 & 4 & slot 5 & 6 & 225 & 182 & 182 & 182 & 0.2 & 0.2 & 0.2 & 0.2 & 0.2 \\
\hline 5 & 5 & slot 6 & 4 & 225 & 182 & 182 & 182 & 0.2 & 0.2 & 0.2 & 0.2 & 0.2 \\
\hline RATE & & & 5.6 & & & & & & & & & \\
\hline
\end{tabular}

The points presented in table are the results of testing the control system which is designed and implemented in which the control system is tested to achieve the desired set point. There are 5 experiments carried out with a set point in the form of a button that is pressed according to the number labeling on the available car slot on a miniature vertical car park device. In table an experiment was carried out with the reference point or starting point in slot 1 then the travel time was calculated for 5 different set points. Voltage measurement is carried out at the input point of the inverter in the form of 1 phase $\mathrm{AC}$ voltage. In addition, the voltage measurement at the inverter output point is also carried out in the form of a 3-phase AC voltage which will supply electricity to the induction motor so that it can rotate.

Table 2. test with initial position in slot 2 Measuring voltage \& electric current on the test

\begin{tabular}{ccccccccccccc} 
Trial & $\begin{array}{c}\text { Set } \\
\text { point }\end{array}$ & $\begin{array}{c}\text { Present } \\
\text { value }\end{array}$ & Time & $\begin{array}{c}\text { input } \\
\text { voltage } \\
\text { (V) } \\
\text { Fasa- } \\
\text { netral }\end{array}$ & R-S & R-T & S-T & Fasa & Net & R & S & T \\
\hline 1 & 1 & slot 2 & 4 & 225 & 182 & 182 & 182 & 0.2 & 0.2 & 0.2 & 0.2 & 0.2 \\
2 & 2 & slot 3 & 4 & 225 & 182 & 182 & 182 & 0.2 & 0.2 & 0.2 & 0.2 & 0.2 \\
3 & 3 & slot 4 & 6 & 225 & 182 & 182 & 182 & 0.2 & 0.2 & 0.2 & 0.2 & 0.2 \\
4 & 4 & slot 5 & 8 & 225 & 182 & 182 & 182 & 0.2 & 0.2 & 0.2 & 0.2 & 0.2 \\
5 & 5 & slot 6 & 6 & 225 & 182 & 182 & 182 & 0.2 & 0.2 & 0.2 & 0.2 & 0.2 \\
& Rate & & 5.6 & & & & & & & & & \\
\end{tabular}


Table 3. test with initial position in slot 3 Measuring voltage \& electric current on the test

\begin{tabular}{ccccccccccccc} 
Trial & $\begin{array}{c}\text { Set } \\
\text { point }\end{array}$ & $\begin{array}{c}\text { Present } \\
\text { value }\end{array}$ & Time & $\begin{array}{c}\text { input } \\
\text { voltage } \\
\text { (V) } \\
\text { Fasa- } \\
\text { netral }\end{array}$ & R-S & R-T & S-T & Fasa & Net & R & S & T \\
\hline 1 & 1 & slot 2 & 16 & 225 & 182 & 182 & 182 & 0.2 & 0.2 & 0.2 & 0.2 & 0.2 \\
2 & 2 & slot 3 & 21 & 225 & 182 & 182 & 182 & 0.2 & 0.2 & 0.2 & 0.2 & 0.2 \\
3 & 3 & slot 4 & 4 & 225 & 182 & 182 & 182 & 0.2 & 0.2 & 0.2 & 0.2 & 0.2 \\
4 & 4 & slot 5 & 8 & 225 & 182 & 182 & 182 & 0.2 & 0.2 & 0.2 & 0.2 & 0.2 \\
5 & 5 & slot 6 & 12 & 225 & 182 & 182 & 182 & 0.2 & 0.2 & 0.2 & 0.2 & 0.2 \\
\hline
\end{tabular}

Table 4. test with initial position in slot 4 Measuring voltage \& electric current on the test

\begin{tabular}{ccccccccccccc} 
Trial & $\begin{array}{c}\text { Set } \\
\text { point }\end{array}$ & $\begin{array}{c}\text { Present } \\
\text { value }\end{array}$ & Time & $\begin{array}{c}\text { input } \\
\text { voltage } \\
\text { (V) } \\
\text { Fasa- } \\
\text { netral }\end{array}$ & R-S & R-T & S-T & Fasa & Net & R & S & T \\
\hline 1 & 1 & slot 1 & 8 & 225 & 182 & 182 & 182 & 0.2 & 0.2 & 0.2 & 0.2 & 0.2 \\
2 & 2 & slot 2 & 6 & 225 & 182 & 182 & 182 & 0.2 & 0.2 & 0.2 & 0.2 & 0.2 \\
3 & 3 & slot 3 & 4 & 225 & 182 & 182 & 182 & 0.2 & 0.2 & 0.2 & 0.2 & 0.2 \\
4 & 4 & slot 5 & 4 & 225 & 182 & 182 & 182 & 0.2 & 0.2 & 0.2 & 0.2 & 0.2 \\
5 & 5 & slot 6 & 6 & 225 & 182 & 182 & 182 & 0.2 & 0.2 & 0.2 & 0.2 & 0.2 \\
& Rate & & 5.6 & & & & & & & & & \\
\end{tabular}

Table 5. test with initial position in slot 5 Measuring voltage \& electric current on the test

\begin{tabular}{ccccccccccccc} 
Trial & $\begin{array}{c}\text { Set } \\
\text { point }\end{array}$ & $\begin{array}{c}\text { Present } \\
\text { value }\end{array}$ & Time & $\begin{array}{c}\text { input } \\
\text { voltage } \\
\text { (V) } \\
\text { Fasa- }\end{array}$ & output voltage(V) & input current(A) & output current(A) \\
netral & R-S & R-T & S-T & Fasa & Net & R & S & T \\
\hline 1 & 1 & slot 1 & 6 & 225 & 182 & 182 & 182 & 0.2 & 0.2 & 0.2 & 0.2 & 0.2 \\
2 & 2 & slot 2 & 8 & 225 & 182 & 182 & 182 & 0.2 & 0.2 & 0.2 & 0.2 & 0.2 \\
3 & 3 & slot 3 & 6 & 225 & 182 & 182 & 182 & 0.2 & 0.2 & 0.2 & 0.2 & 0.2 \\
4 & 4 & slot 5 & 4 & 225 & 182 & 182 & 182 & 0.2 & 0.2 & 0.2 & 0.2 & 0.2 \\
5 & 5 & slot 6 & 4 & 225 & 182 & 182 & 182 & 0.2 & 0.2 & 0.2 & 0.2 & 0.2 \\
\hline
\end{tabular}

Table 6. test with initial position in slot 6 Measuring voltage \& electric current on the test

\begin{tabular}{ccccccccccccc}
\hline Trial & $\begin{array}{c}\text { Set } \\
\text { point }\end{array}$ & $\begin{array}{c}\text { Present } \\
\text { value }\end{array}$ & Time & $\begin{array}{c}\text { input } \\
\text { voltage } \\
\text { (V) } \\
\text { Fasa- } \\
\text { netral }\end{array}$ & R-S & R-T & S-T & Fasa & Net & R & S & T \\
\hline 1 & 1 & slot 1 & 4 & 225 & 182 & 182 & 182 & 0.2 & 0.2 & 0.2 & 0.2 & 0.2 \\
2 & 2 & slot 2 & 6 & 225 & 182 & 182 & 182 & 0.2 & 0.2 & 0.2 & 0.2 & 0.2 \\
3 & 3 & slot 3 & 8 & 225 & 182 & 182 & 182 & 0.2 & 0.2 & 0.2 & 0.2 & 0.2 \\
4 & 4 & slot 4 & 6 & 225 & 182 & 182 & 182 & 0.2 & 0.2 & 0.2 & 0.2 & 0.2 \\
5 & 5 & slot 5 & 4 & 225 & 182 & 182 & 182 & 0.2 & 0.2 & 0.2 & 0.2 & 0.2 \\
& Rate & & 5.6 & & & & & & & & & \\
\end{tabular}


Based on the results of the discussion that has been done and described above, the data obtained can be retrieved and analyzed to then draw conclusions. The results of the visual analysis carried out on the mechanical components are made based on the design image that the vertical car park prototype can accommodate 6 cars consisting of 6 maximum capacity slots. Time required by the automatic prototype vertical car parking system is the fastest is 4 seconds and the longest is 8 seconds, while the intermediate time is 6 seconds. The average time obtained by the automatic vertical car parking prototype system is 5.6 seconds.

\section{CONCLUSION}

The mechanical design implemented in the automatic parking system prototype can accommodate 6 units of cars arranged vertically upwards. The fastest time to call a miniature car in a vertical car parking prototype is 4 seconds and the longest is 8 seconds with an average time of 5.6 seconds.

\section{REFERENCES}

[1] Adams, G. A., King, L. A., \& King, D. W. (1996). Relationships of job and family involvement, family social support, and work-family conflict with job and life satisfaction. Journal of applied psychology, 81(4), 411.

[2] Boban, M., Kousaridas, A., Manolakis, K., Eichinger, J., \& Xu, W. (2018). Connected roads of the future: Use cases, requirements, and design considerations for vehicle-to-everything communications. IEEE vehicular technology magazine, 13(3), 110-123.

[3] Ellin, A., \& Dolsak, G. (2008). The design and application of rotary encoders. Sensor Review.

[4] Heimberger, M., Horgan, J., Hughes, C., McDonald, J., \& Yogamani, S. (2017). Computer vision in automated parking systems: Design, implementation and challenges. Image and Vision Computing, 68, 88-101.

[5] Huh, J. H., Otgonchimeg, S., \& Seo, K. (2016). Advanced metering infrastructure design and test bed experiment using intelligent agents: focusing on the PLC network base technology for Smart Grid system. The Journal of Supercomputing, 72(5), 1862-1877.

[6] Kobus, M. B., Gutierrez-i-Puigarnau, E., Rietveld, P., \& Van Ommeren, J. N. (2013). The on-street parking premium and car drivers choice between street and garage parking. Regional Science and Urban Economics, 43(2), 395-403.

[7] Krasinski, P., Pękosławski, B., \& Napieralski, A. (2013, June). IEEE 802.15. 4 wireless network application in real-time automation systems. In Proceedings of the 20th International Conference Mixed Design of Integrated Circuits and SystemsMIXDES 2013 (pp. 508-511). IEEE.

[8] Nirwan, T. Y., Waghmare, A. S., Rahate, G. R., Bhujadi, K., Saiyyad, A. A., Shahu, A., \& Anjikar, A. D. (2016). Introduction to vertical multistage car parking system. Int. Research J. of Engineering and Technology (IRJET), 3(4), 1492-1494.

[9] Orrie, O., Silva, B., \& Hancke, G. P. (2015, November). A wireless smart parking system. In IECON 2015-41st Annual Conference of the IEEE Industrial Electronics Society (pp. 004110004114). IEEE.

[10] Sheridan, T. B. (1992). Telerobotics, automation, and human supervisory control. MIT press.

[11] Stojeev, M. K. (2003). John W. Webb, Ronald A. Reis: Programmable logic controllers: Principles and applications, 5e. Facta universitatis-series: Electronics and Energetics, 16(2), 285-287. 